\title{
Literatura, pensamiento político e independencia en América Latina. Los «Diálogos» de José Cecilio Del Valle (Guatemala, 1821)
}

\author{
Mariana Alberto \\ Universidad Nacional del Litoral, Argentina \\ mariana.b.alberto@gmail.com
}

Resumen. Los dirigentes de las excolonias españolas en América, con la independencia, asumieron, entre otras, la tarea de construir el Estado y la nación. Así, durante el siglo XIX bubo diversas propuestas elaboradas por politicos e intelectuales de varios países latinoamericanos. En ese contexto, más allá de observar varias coincidencias fundamentales y algunas diferencias notables, es interesante constatar que muchos de estos pensadores utilizaban la literatura como un arma politica en la lucha y en los debates por sus ideas. Uno de los medios más empleados fue la prensa, otro, la construcción de diálogos ficticios entre personajes históricos, como los que muy tempranamente realizara Bernardo de Monteagudo entre Atabualpa y Fernando VII. Sin poder analizarlos todos, este trabajo es una primera reflexión sobre una serie de estos diálogos decimonónicos publicados por el hondureño José Cecilio del Valle, «Diálogos de diversos muertos sobre la Independencia de la América», por considerarlo una propuesta clave a la bora de desandar el camino de la explicación del complejo entramado entre literatura, pensamiento político e independencia en las sociedades latinoamericanas en las primeras décadas del siglo XIX.

Palabras clave: literatura; politica; sociedades latinoamericanas. 
Literature, Political Thought and Independence in Latin America. The “Dialogues” of José Cecilio del Valle (Guatemala, i82 I)

Abstract. Having won independence, the leaders of the former Spanish colonies in America took on the task, among others, of building their respective states and the nations. As a result, during the nineteenth century many politicians and intellectuals from several Latin American countries put forward various proposals in this regard. Beyond several fundamental coincidences and certain notable differences, it is interesting to note that many of these thinkers used literature as a political weapon in the struggle and in the debates for their ideas. One of the most widely used media was the press, another, the construction of fictitious dialogues between bistorical figures, such as those that Bernardo de Monteagudo created very early on between Atabualpa and Fernando VII.

Although unable to analyze them all, this work is a initial reflection on a series of these nineteenth-century dialogues published by the Honduran José Cecilio del Valle, which is entitled "Dialogues by various dead people about the Independence of America" and considered a key text for retracing and explaining the complex framework between literature, political thought and independence in Latin American societies in the first decades of the 19th century.

Keywords: literature; politics; Latin American societies.. 


\section{Serendipia}

Este artículo es una serendipia (serendipity) surgida en el desarrollo de una investigación aún en curso sobre los proyectos de unidad latinoamericana elaborados en el siglo xix. Dichos proyectos son analizados en la media duración que transcurre entre el fin de la dominación colonial en las décadas de 1810 y 1820 y la coyuntura en la que comienzan a definirse más o menos formalmente los Estados poscoloniales surgidos de la disgregación de los cuatro virreinatos (Nueva España, Perú, Nueva Granada, Río de la Plata), circa las décadas de 1860 y 1870.

Conforme las ideas prevalentes en la época, los modelos factibles eran dos: monarquía constitucional y república (federal o centralista). La opción por uno u otro incluía otro problema no menor: definir el alcance territorial de la organización política reemplazante del Estado colonial abolido. El impulso inicial apuntaba a mantener la espacialidad de los cuatro virreinatos, es decir, cuatro Estados poscoloniales. Empero, hubo quienes propusieron una escala mayor, abarcadora de la totalidad del espacio colonial, comenzando por el pionero proyecto de Francisco de Miranda (tan temprano como en 1790, reformulado en 1801), y retomado, con coincidencias y diferencias, por Juan Egaña, José Cecilio del Valle, Simón Bolívar, Bernardo de Monteagudo, Juan Bautista Alberdi, Francisco Bilbao y José María Torres Caicedo, entre los principales. Para todos ellos, el desiderátum era la unidad de la América del Sur, expresión esta última que todavía a mediados del siglo xix hacía referencia a todo el espacio que había ocupado el Imperio español en el continente, desde el norte de México (incluyendo los vastos territorios arrebatados por Estados Unidos en la década de 1840) hasta el estrecho de Magallanes.

Obviamente, el tratamiento de esos proyectos escapa a los límites y la intencionalidad del presente artículo. Se trae la cuestión a colación tan solo para dar cuenta de dónde surgió la serendipia. Es que en la indagación sobre los proyectos de unidad hispanoamericana, primero, latinoamericana, más tarde - aunque no deja de ser una cuestión relevante la no inclusión de Haití, primera república independiente dentro del espacio colonial latino y pieza clave para la empresa libertadora de Bolívar-, era necesario indagar también sobre los autores de aquellos proyectos. Al analizar la actuación de José Cecilio del Valle, en particular su obra escrita, nos llamaron la atención sus escritos periodísticos, en particular sus imaginados diálogos entre muertos históricamente destacados, algunos de ellos, como Charles Louis de Secondat (más conocido como barón de Montesquieu) y Jean-Jacques Rousseau, temporalmente más próximos a los años de vida de Valle. Ello llevó a indagar al respecto. 


\section{El diálogo: una forma literaria como recurso político}

Una de las estrategias discursivas de los líderes independentistas fue la apelación a diversas formas literarias para llegar a un público numéricamente escaso por las altas tasas de analfabetismo, pero cualitativamente con poder de decisión. Una de las formas fue imaginar y presentar diálogos ficticios entre personajes históricos, incluso espacial y temporalmente distanciados. Se trata de algo bien conocido: el empleo de la literatura, o de formas literarias, como un arma política en la lucha y en los debates por sus ideas. Uno de los medios preferidos fue la prensa, según prueba la miríada de periódicos creados a lo largo del continente, la mayoría de existencia breve ${ }^{1}$. Es que, como bien dice Elena Altuna, aquellos hombres creían en el poder de la escritura.

En las primeras décadas del siglo xix persistía la apelación a figuras o hechos de la Antigüedad greco-romana como forma elíptica para describir, analizar y criticar la situación política de la época, y, así, procurar burlar la censura o escapar a alguna forma de sanción. También supo apelarse a una forma literaria de larga data, iniciada por griegos y continuada por romanos: el diálogo (v. gr., Platón, Cicerón, Tácito). Dicha forma pasó del contenido filosófico originario al didáctico durante la llamada Edad Media, resurgió al estilo de la Antigüedad en el Renacimiento, para perder importancia a partir de la segunda mitad del siglo XVI, desplazada por nuevas formas como el ensayo y el artículo periodístico, aunque persistente hasta avanzado el siglo XIX.

Una de las formas literarias a las que apelaron algunos independentistas fue la del diálogo entre muertos. No estaban solos. Éric Volant (2012) ejemplifica con cinco autores que les precedieron en Europa: Bernard le Bovier de Fontenelle (1657-1757), autor de varios diálogos que relatan conversaciones ficticias entre Séneca y Paul Scarron (escritor satírico francés del siglo xvir), Sócrates y Montaigne, Nicolas Boileau, Dialogue sur les héros de roman (1688), Federico II, rey de Prusia (1712-1786), Dialogue des morts entre Madame de Pompadour et la Vierge Marie, y François Fénelon (1651-1715), Dialogue des morts para la educación del duque de Borgoña, nieto de Luis XIV. Con posterioridad, ya avanzado el siglo xIx, Ernest Renan, Dialogue des morts, entre Corneille, Racine, Boileau, Voltaire, Diderot y Camillus.

1 Félix Muradás García da cuenta de 105 títulos publicados entre 1806 y 1830 en Chile, Colombia, Guatemala, México, Perú, Provincias Unidas del Río de la Plata (Argentina y Uruguay) y Venezuela. Véase su La época de las independencias: Hispanoamérica 1806-1830, Madrid, Servicio de Información Bibliográfica de la Biblioteca Nacional de España (BNE), s. f. 


\section{El diálogo de los muertos}

Como forma literaria, los «diálogos entre muertos» fueron una creación original de Luciano de Samósata ${ }^{2}$, aunque Éric Volant (2012) sostiene que le precede Homero (circa siglo vir a. C.) al describir la nekyia (o nekuia), un viaje al Hades, en el canto XI de la Odisea, donde Ulises, después de haber dado libaciones a los muertos, convoca a Tiresias y a Anticlea, su madre.

Luciano imaginó, en 166-167, treinta conversaciones entre, básicamente, dioses o personajes mitológicos griegos con otros, reales o imaginados, de la Grecia clásica y helenística, reunidas en su obra titulada, justamente, Diálogos de los muertos. Tuvieron lugar en el Hades, el inframundo donde reposaban los muertos. Los abordó con un notable sentido de humor (de hecho, Luciano es considerado uno de los primeros humoristas), o, como dice Susana Hört (2006: 92), apelando a «recursos de humor situacional, parodia, humor verbal».

Según Carolina Carvajal (2017), se propone «el "diálogo de los muertos" como una alegoría del lugar de enunciación del autor». En el caso que ella analiza, el de Juan Rafael Allende - un político, intelectual, periodista, escritor chileno de fines del siglo xIX-, «[1]a gran libertad de los muertos y su tono provocador conduce a una crítica lúcida y profunda de la sociedad chilena» de dicho siglo. Se trata de una construcción dialógica «en una dimensión contestataria y en una permanente confrontación con los grupos sociales emergentes y con la iglesia católica en el contexto de la lucha por secularizar el Estado» ${ }^{3}$.

Es un buen punto de partida: libertad de expresión adjudicada a los muertos, contracara de la que, elípticamente, carecen los vivos; tono provocador; crítica lúcida y profunda; confrontación con grupos sociales y con la Iglesia católica. Como se verá, tópicos presentes en los «Diálogos» de José Cecilio del Valle.

Carvajal apela a la autoridad de algunos autores clave: Lisa Andries (2004), Mijail Bajtin (1986), João Domingues (2012), Ariane Eissen (2007) y Michael Henrichot (2008). De las invocaciones que realiza, aquí se retendrán unas pocas. La primera remite a Bajtin: el diálogo de los muertos es, para el autor ruso, un género liberado «de todos los convencionalismos, estamentos, obligaciones y reglas de la vida normal», esto es, acota Carvajal, «una vida donde va a primar la permisividad, tanto en el accionar como en el hablar» (2017: 5; cursivas nuestras).

A su vez, para Lise Andries (2004), el diálogo de los muertos es un género donde el papel protagónico lo tiene la disputa, género en el cual — señala Mi-

2 Luciano nació en Samósata — por entonces ciudad siria dentro del Imperio romano, actualmente Turquíaen 125 y falleció en algún momento después de 180 en lugar desconocido. Su lengua materna era el griego.

3 La novela en cuestión es Cosas de los vivos contadas por los muertos. 
chael Henrichot (2008, citado por Carvajal, 2017) - la naturaleza y el número de quienes dialogan, como la extensión de los diálogos, carecen de rigidez.

La conclusión de Carvajal es que los diálogos de los muertos «son parte de un momento histórico específico [...] que responden a distintas condiciones estéticas, ideológicas, políticas, las que a su vez favorecen la recuperación de esta forma literaria» (2017: 7-8).

Retengamos los principales rasgos que destacan de su síntesis: libertad de expresión, tono provocador, posiciones contestatarias, liberación de convencionalismos, permisividad del decir y del hacer, disputa.

Según Volant (2012), un diálogo de los muertos puede identificarse con algunos caracteres formales bastante bien definidos: breve entrevista en prosa de dos muertes anacrónicas que se encuentran en el inframundo, si bien se pueden dar vivos por muertos, elegir dos contemporáneos, o bien ser un largo diálogo que reúne a numerosos personajes. Citando a Michel Henrichot ( La fiction infernale dans les Dialogues des morts», en Arlette Bouloumié, Les Vivants et les Morts. Litteratures de l'entre-deux-mondes, Imago, 2008, pp. 55-66), añade: «Entre los rasgos definitivos destacan la mención y la representación de los infiernos, rasgo constante, a menudo simplemente esbozado pero imperativo para que se pueda definir un diálogo como un diálogo de los muertos».

Ariane Eissen dirigió el número 22 de la revista Otrante (otoño 2007), dedicado, precisamente, a los diálogos de muertos. En el resumen del contenido de dicho número se dice:

Definido como la puesta en escena de las palabras de personajes ilustres del más allá, el diálogo de los muertos es una forma menor pero recurrente de la cultura europea» desde la Antigüedad griega hasta la actualidad (Giorgio Manganelli, Tom Stoppard, Enzo Cormann, Milan Kundera), pasando por Bernard Le Bovier de Fontenelle y François Fénelon, en los siglos xvir y xviIr. Se trata de muertos que hablan desde fuera de tiempo y lugar. Es «una literatura de otro lugar», evocadora de «un mundo y una temporalidad accesibles sólo a la imaginación, con la particularidad de que la frontera que nos separa de este otro lugar es simbólicamente muy fuerte en la imaginación humana, ya que coincide con el contorno de su otra parte, representación de la vida (del espacio vital autorizado)». El diálogo de los muertos, acota Eissen, termina siendo «el lugar de una valoración crítica (filosófica y moral, pero también estética, política o historiográfica)». E, inquietante, se pregunta: «¿Serían estas muertes nuestros dobles reflexivos?».

Para Vian Herrera (2001: 158), el diálogo de los muertos es un «tipo especial de interacción verbal» que, en cuanto que encuentro oral, es un género literario 
(un texto); un género literario argumentativo (intención de persuasión entre los dialogantes o, al menos, de uno de ellos), y una argumentación interactiva (una construcción explícita y cooperativa del texto entre dos o más locutores). Para su análisis son pertinentes la retórica, la dialéctica, la teoría de la argumentación, la lingüística, el estudio de las interacciones verbales. Obviamente, no es nuestro caso, donde los textos, en cambio, interesan ser interpelados desde el análisis sociológico, en los términos planteados por Luis Enrique Alonso (1998, capítulo 6).

Susana Hörl (2006ः 92) apunta que existen dos tipos contrastantes de diálogos de muertos: uno de ellos es entre seres mitológicos; el otro, el que nos interesa a nuestros fines, es típico de los temas históricos y se caracteriza porque en él «uno de los interlocutores introduce una narración amplificada — casi teóricaque pareciera justificarse sin embargo dentro del marco estructural e ideológico».

En nuestra investigación encontramos dos propulsores de la unidad latinoamericana que apelaron al diálogo como recurso político: Bernardo de Monteagudo (1789-1825), figura clave en la acción de José de San Martín y Simón Bolívar, y José Cecilio del Valle (1777-1834). Monteagudo escribió, en 1808, al conocerse la invasión de España por las tropas francesas, el «Diálogo entre Atahualpa y Fernando VII en los Campos Elíseos», dos gobernantes desplazados del poder por la conquista del Incario, el primero, y la ocupación militar napoleónica, el español.

Valle fue autor de los «Diálogos de diversos muertos sobre la Independencia de la América», objeto de análisis en esta contribución. Monteagudo puso a dialogar a un hombre muerto y uno vivo, apartándose del modelo clásico. Valle, a su vez, hizo a ocho, en díadas, todos muertos.

A propósito de Monteagudo, Elena Altuna, al analizar el pensamiento de este, se detiene en el diálogo entre muertos, o, como ella prefiere, entre sombras, considerando al elaborado por el tucumano como expresión representativa de una literatura heterogénea característica de la coyuntura independentista. «Su título expresa la confluencia entre el Neoclasicismo - por el cual se reponen el diálogo, género didáctico ensayístico caracterizado por ser vehículo de cuestionamiento e indagación de problemáticas contemporáneas [siguiendo la autora a Antonio García Berrio y Javier Huerta $\mathrm{Calvo}^{4}$ ] y la literatura de visiones grecolatina- y un aporte americano: el Incaísmo» (Altuna, 2002: 2).

4 Antonio García Berrio y Javier Huerta Calvo, Los géneros literarios: sistema e historia, Cátedra, Madrid, 1992. 


\section{José Cecilio del Valle: breve semblanza}

José Cecilio del Valle nació en la villa Jerez de Choluteca (hoy Choluteca, Honduras) el 22 de noviembre de 1777, siendo sus padres Ana Gertrudis del Valle y José Antonio Díaz del Valle, criollos, terratenientes, miembros de una familia de hijodalgos, por tanto, con privilegios, pese a su condición de americanos. Los del Valle fueron una familia de hacendados, políticos y funcionarios durante la colonia y los tiempos de la independencia. José Cecilio realizó sus primeros estudios con los hermanos betlemitas y en el Colegio Tridentino. En 1791 ingresó en la Real y Pontificia Universidad de San Carlos Borromeo (actual Universidad de San Carlos de Guatemala), graduándose de bachiller en Filosofía, en 1794, de bachiller en Derecho Civil y Canónico en 1799 y en 1803, de licenciado en Abogacía, profesión que ejerció de inmediato, «más por necesidad económica que por vocación», ya que no heredó fortuna de su padre (Gómez, 2010: 15). En 1812 se casó con Josefa Valero, hondureña, con la cual tuvo tres hijos: María Dolores, María Josefa y Bernardo Macabeo.

Su formación fue, disciplinariamente, muy amplia, enciclopedista: ciencias naturales, ciencias políticas, derecho, economía, finanzas, geografía, historia, idiomas, matemáticas. Su tesis para obtener el título de bachiller en Filosofía se ocupó de una cuestión de la física: la electricidad. En ella demostró conocer a autores «como Kepler, Galileo, Newton, Gassendi, Stevin y Becker, entre otros» (Gómez, 2010: 13). Mantuvo intercambio epistolar con Jeremy Bentham, el conde Giuseppe Pechio (liberal italiano exiliado en Suiza tras la Revuelta del Piemonte, en 1821, y luego en el Reino Unido), Álvaro Flores Estrada (abogado, economista y político español, liberal, masón, exiliado en Londres al regreso de Fernando VII al trono) y Alexander von Humboldt. Según Gómez, la relación más fluida fue con Bentham.

Para Mario García Laguardia, Valle fue un ilustrado completo, un hombre que, ya maduro, fue «posiblemente el más representativo de su región. Aceptar la física de Newton, la psicología de Locke y Condillac y las concepciones políticas de Rousseau y Montesquieu, era afiliarse a la modernidad»(Valle, 1982: ix).

Valle fue un decidido defensor de la libertad de expresión, impulsor de la educación popular y generalizada, y, dato no menor, la plena incorporación de los indígenas a la sociedad. Fue opositor a la diferenciación social por el color de la piel argumentando así: «Era cobrizo el color del indio y más claro el de los españoles. Pero más blancos y más rubios que los españoles eran los alemanes, y cuando la casa de Austria quiso dominar a España, los españoles se levantaron contra ella y proclamaron a la de Borbón. El color no es título de superioridad o esclavitud. Cobrizo, moreno o blanco eres hombre, americano infeliz: y la esencia 
de hombres te da derechos imprescriptibles» (en el artículo «América», 1821, en Gómez, 2010: 79). Hoy puede decirse, con Luigi Ferrajoli, que debían tener esos derechos fundamentales por el mero hecho de ser personas.

La carrera política de Valle se inició a fines del régimen colonial, hacia 1803, y se prolongó hasta su muerte, en 1834. No estuvo exenta de ser interpretada conflictiva, contradictoriamente, en primer lugar, por sus propios coetáneos. García Laguardia sostiene que hubo dos momentos claramente diferenciados, que parecen contradictorios, pero que no lo fueron: de fidelidad a la Corona, uno; decididamente republicano e independentista, el otro. No encuentra contradicción porque la lealtad a la Corona había sido, en rigor, con el despotismo ilustrado y reformista borbón, del que fue parte un grupo de intelectuales esclarecidos como instrumento de transformación. García Laguardia acota que el reformismo estatal fue siempre basal en el pensamiento político del centroamericano (Valle, 1982: xxvi).

Puede decirse, sintéticamente, que fue un liberal reformista, en ocasiones más radical que otros contemporáneos, sin llegar a ser un revolucionario. En ese sentido rayó alto su propuesta de la unión de las excolonias españolas en una única entidad política - la Patria Grande independiente-, con igualdad entre las partes constitutivas y la distribución geográfica de los centros económicos, políticos y religiosos, manteniendo «las peculiaridades regionales de cada nación», limitando así el poder del Gobierno central (Gómez, 2011:88).

La propuesta unionista de José del Valle fue explícitamente formulada en un artículo publicado en el número 24 (1 de marzo de 1822) de su periódico El Amigo de la Patriaः «Soñaba el Abad de San Pedro y yo también sé soñar».

Puede acordarse con Gómez (2011: 147) que fue un hombre que aunó la condición de «hábil político» con la de intelectual, «destacándose en estas dos facetas con igual éxito». El azar le jugó una mala pasada: falleció cuando debía asumir la presidencia de la República Federal Centroamericana, cargo para el que había sido elegido. «Para ello se había preparado toda su vida y era el cargo que más ambicionaba desempeñar, aunque como otras veces en su vida se quedó en el umbral» (Gómez, 2010: 54). La muerte le evitó asistir a la desafortunada disolución de la federación, en $1838^{5}$.

5 Escapa a los límites e intención de este artículo siquiera reseñar el contexto de la lucha por la independencia y construcción estatal poscolonial. La bibliografía al respecto es vastísima. Síntesis pueden verse en Timothy Anna (1985 y 2003), Waldo Ansaldi y Verónica Giordano (2016, capítulo 3), Tulio Halperin Donghi (1985, segunda y tercera partes) y Julio César Pinto Soria (1993), entre muchos otros. 


\section{«Diálogos de diversos muertos sobre la Independencia de la América»}

Del Valle imaginó cuatro «Diálogos», publicados en 1821 en El Amigo de la Patria: 1. ${ }^{\circ}$, Cristóbal Colón y Jean-Jacques Rousseau; 2. Hernán Cortés y el barón de Montesquieu; $3 .^{\circ}$ Carlos I y Carlos III, y 4 ${ }^{\circ}$ Filántropo y Palemón.

Primer punto: ¿cuál fue el lugar de enunciación de Valle, es decir, su momento histórico específico? Escribió en la por entonces aún Capitanía General (o Reino) de Guatemala, sujeta al poder colonial de una España que vivía el Trienio Constitucional liberal (1820-1823), que puso límites al despotismo de Fernando VII, que logró recuperar con el apoyo de los Cien Mil Hijos de San Luis, una fuerza invasora francesa comandada por Louis-Antoine de France, duque de Angulema. Violando los términos del acuerdo de paz, Fernando VII reprimió fuertemente a los liberales y restauró el absolutismo (la Década Ominosa, 1823-1833). Al mismo tiempo, 1821 fue el año en que, finalmente, los mexicanos proclamaron la independencia (27 de septiembre), adoptando la forma de gobierno monárquicocatólica, breve experiencia (1821-1823) que precedió a la república federal. Es decir, Valle escribió los «Diálogos» en un momento histórico de alta conflictividad e incertidumbres.

En el movimiento independentista mexicano destacaban dos nombres: Agustín de Iturbide, un militar nativo que al frente de las tropas realistas combatió a las fuerzas insurgentes durante la denominada Resistencia (1816-1821), en cuyas filas prevalecía Vicente Guerrero, el segundo nombre destacable. Ambos jefes superaron el enfrentamiento mediante la firma del Plan de Iguala (febrero de 1821), acuerdo que estableció cuatro principios: independencia de México; mantenimiento de la monarquía, con Fernando VII u otro miembro de la Corona como rey; establecimiento de la religión católica como única, y unión de todas las clases sociales. Religión, Independencia y Unión fueron principios que devinieron Tres Garantías, levantadas por el Ejército para sostener al Gobierno.

Los acontecimientos en México plantearon un fuerte dilema entre los centroamericanos respecto del camino que seguir. Algunos se decantaron por la proclamación de la independencia; otros, entre los cuales estaba Valle, entendían que no estaban dadas todas las condiciones para tomar esa decisión. Finalmente, el 15 de septiembre de ese año, doce días antes que los mexicanos, Guatemala declaró la independencia. Irónicamente, Valle fue el redactor del acta.

Valle escribió sus «Diálogos» en un contexto de fuertes enfrentamientos políticos, ideológicos y filosóficos en España, México y Centroamérica. Aunque el clima de ideas parecía menos brutal que el imperante hasta el levantamiento militar 
liberal en España - mas no en México y Centroamérica-, Valle redactó unos breves textos que rompieron su hasta entonces estilo moderado, reemplazado por un tono más enérgico y agresivo que fue un corto momento, pues luego retornó al primero (Gómez, 2010:25). El artilugio literario de poner en boca de los muertos lo que el autor vivo no se atrevía a asumir era un modo (algo ingenuo si se quiere) de preservarse ante una eventual represión del poder. Empero — añade Gómez- las expresiones del autor no eran otra cosa que parte del bagaje de su «argumentación ilustrada» acerca del gobierno colonial y el derecho de los americanos a independizarse.

\section{Cristóbal Colón dialoga con Jean-Jacques Rousseau}

El primero de los «Diálogos» imaginados, entre Colón y Rousseau, fue también el más radical de los cuatro. No parece una elección caprichosa o casual. Remite al comienzo de la historia que por entonces enfrentaba a españoles y americanos y donde los independentistas cuestionaron más o menos radicalmente los supuestos derechos de conquista de los europeos. Ya lo habían hecho, por ejemplo, Monteagudo, en su diálogo entre Atahualpa y Fernando VII (1825), y Mariano Moreno en su artículo «Sobre las miras del Congreso» (1810). En ambos, obviamente, la fuente era El contrato social.

Valle, en el comienzo mismo, le hace pronunciar a Colón expresiones autoelogiosas de su «descubrimiento» de América, en cuanto que portador de civilización. La réplica del ginebrino es dura:

La historia de este descubrimiento no es muy hermosa para el género humano [...]. Indios inocentes, felizmente ignorantes de la Europa, vivían en esa bella porción de la tierra. No hacían daño al asiático, al africano, ni al europeo [... ].

Pero tu descubrimiento fue funesto para la especie humana. Los españoles, los ingleses, los portugueses, los franceses, los rusos, se volvieron, fueron conquistadores inhumanos. La fuerza holló todos los derechos y sacrificó lo más sagrado. Un mundo entero fue víctima de la ambición y de la codicia. [...] El europeo abrió los minerales de la América; y el oro y la plata, derramándose por el mundo, corrompieron a todos los hombres. Guerras sucesivas en Europa, tiranías horrorosas en América, han sido el cuadro triste del universo. Se subyugó a los americanos para gozar de sus riquezas; se hizo esclavo al africano para tener operarios que las extrajesen; se corrompió al asiático llevando a sus puertos las que se extraían; se degollaron unos a otros los europeos por ser poseedores exclusivos de ellas. El mundo entero sufre por tu falaz descubrimiento. ¡Qué hora tan triste aquella en la que llegaste a hacerlo! (Valle, 1982: 187-188; aquí y en adelante, cursivas nuestras). 
En el contexto de la época, el cuestionamiento de Valle a la conquista y colonización de América sonaba fuerte, duro. Denunciaba el carácter económico rapaz de ese proceso que subyugó a americanos y africanos para apropiarse de riquezas que solo favorecieron a europeos, todo a un alto costo a ambos lados del Atlántico, es decir, el proceso que años después Karl Marx llamaría acumulación originaria del capital.

En la inmediata continuidad del diálogo, Valle abordó una cuestión delicada para una época de intolerancia: ya no el papel de la Iglesia en la conquista, sino el de la religión. Le hace decir a Colón que, si no hubiera sido por él:

La América ignoraría hasta ahora la religión divina de España. Continuaría idólatra, adorando al sol, a... Las luces del Evangelio no hubieran iluminado a los Andes.

La respuesta que pone en boca de Rousseau es contundente y debe haber soliviantado a más de uno:

[...] Hacer uso de la fuerza para extender la religión es hacer odiosa a la misma religión. Perseguir, matar, quemar para propagar el Evangelio, es ofender a la religión e insultar a la razón. La Europa sería un pueblo de dioses si respetando los derechos de la América se hubiera limitado a dar luces puras al americano. [...] Conquistar, hacer esclavos para plantear la religión, es hollar la moral para predicar el dogma; es destruir la caridad para establecer la fe [...]. Pero sacrificó a la porción más desvalida de la especie, y su oprobio será eterno en todos los siglos (Valle, 1982: 188-189).

Se trata de un texto contundente contra la Inquisición española —a la que aludía con perseguir, matar, quemar por profesar otra religión-, institución tristemente célebre creada por los Reyes Católicos en 1478 y persistente hasta 1808 -abolición napoleónica por los decretos de Chamartín, ratificada por las Cortes de Cádiz en 1813 - , restaurada por Fernando VII en 1814, abolida por tercera vez en 1820 y definitivamente en 1834 . Es muy fuerte el cuestionamiento de la religión católica, aunque no dijera explícitamente que se trataba de ella, si bien es obvio. No se encuentra nada siquiera parecido en el «Diálogo» del más radical Monteagudo. A Valle se le ha atribuido la condición de masón, la cual, de ser verídica, contribuiría a explicar su crítica.

Enseguida, Valle le hace decir a Colón que la marcha de la naturaleza es que las naciones poderosas sean conquistadoras de las desvalidas. También en este tópico, Valle cuestiona el principio con los argumentos que le atribuye a Rousseau.

El más fuerte no es jamás bastante fuerte para ser siempre señor si no erige su fuerza en derecho y la obediencia en deber [... $]$. Elige el extremo que quieras. $\mathrm{O}$ 
es derecho la fuerza, o no lo es. En el primer caso, América puede pronunciarse independiente, conquistar a España y hacer esclavos a los españoles porque su fuerza es mayor que la de la Península. En el segundo, la conquista de América es injusta y no da derecho a los europeos (Valle, 1982: 189).

En el diálogo imaginario entre ambos muertos, Colón se empeña en justificar y defender la ocupación colonial de América diciendo:

Los indios reconocieron de grado el imperio de los reyes católicos y sus sucesores. Voluntariamente se juraron vasallos de Fernando y de Isabel. Si la conquista no da derechos, ¿podrá dejar de darlos la voluntad?

Es interesante el contrapunto, pues el argumento de la sumisión de los conquistados como voluntaria es una falacia sin asidero histórico. En la respuesta que el autor le adjudica al imaginario Rousseau prima un razonamiento basado en la razón, amén de una inicial constatación empírica:

El cálculo de cadáveres que hizo el obispo de Chiapas [Bartolomé de las Casas ${ }^{6}$ ] atesta lo contrario. Yo no creo que sea obra de la voluntad libre de un hombre la esclavitud de un mismo hombre [...]. Decir que un pueblo entero se somete espontáneamente, es suponer un pueblo de dementes; y la demencia no funda derechos. Aun permitiendo que cada uno pudiera enajenarse a sí mismo, es claro que no podría enajenar a sus hijos. Los hombres nacen libres. Si los caciques, mesagüales, etc. quisieron vender su libertad a los Cortés y los Almagros, ¿tendrían derecho para sacrificar la de sus descendientes? (Valle, 1982: 189-190).

Valle avanza luego en el cuestionamiento de la oposición orden/desorden, aunque sin llegar a proponer que lo contrario de un orden es la propuesta de otro orden, tal como sostienen Waldo Ansaldi y Verónica Giordano (2016:37-46 et passim). El hondureño lo hace haciéndole decir a la sombra Colón que la independencia turbaría el reposo y la tranquilidad dados por la sujeción de América a Europa, con la obvia consecuencia de la lucha y el derramamiento de sangre, que afectaría a «los campos de la fertilidad y los minerales del oro».

La sombra Rousseau rebate:

Un déspota mantiene en reposo y tranquilidad el estado que gobierna. Pero, ¿qué es lo que ganan sus vasallos, si las guerras que hace nacer su ambición, si su codicia insaciable y las vejaciones de su ministerio hacen más víctimas que las que harían sus disensiones interiores? ¿Qué es lo que ganan si esa misma tranquilidad que ponderan es una de sus miserias? En los calabozos viven tranquilos los presos; ¿y dirías que son felices? [... [ La tranquilidad de un estado, donde la hay porque cada uno de los individuos que lo componen respeta

6 También Monteagudo había apelado a las Casas como fuente, habiendo sumado al Inca Garcilaso. 
religiosamente los derechos de los demás, es la tranquilidad del cielo; la suma de la felicidad; el bello político de las naciones. Pero la tranquilidad del país donde existe porque los opresores no permiten movimiento alguno de los oprimidos que van sacrificando diariamente, es la tranquilidad de las cárceles; el silencio de los calabozos; el reposo de los cementerios. En un día de conmoción hay sangre y muertes. Pero en un año, un decenio, en un siglo de despotismo, jcuántos cadáveres manda al sepulcro la mano dura de la tiranía! (Valle, 1982: 190).

Allí, Valle reivindicaba, con otras palabras, la violencia revolucionaria. Admitía que provoca muertes, pero muchísimas menos que las producidas por la opresión. Reivindicaba también el derecho de los oprimidos a manifestarse, y exigía que el poder respetara los derechos de los demás. Cuestionaba, pues, al orden que reprimía, oprimía, avasallaba, mataba. Con lenguaje elíptico, reivindicaba el derecho a la rebelión en situaciones de opresión, de tiranía.

Más adelante, en el mismo diálogo entre Colón y Rousseau, Valle ponía en boca del segundo la postura que levantaban los opresores, los enemigos de la democracia:

Los gobiernos democráticos no son posibles; los representativos son tumultuosos. Solamente los absolutos son tranquilos y energéticos Preferid el interés del mínimo al bien del máximo [... . Reunid soldados sacados del pueblo para tener oprimido al mismo pueblo.

En el final, Valle-Rousseau exponía la doble vara del poder, del orden establecido, para juzgar:

Descubrir un mundo para que sean envilecidos y hollados sus habitantes; proponer su conquista; cooperar a ella; recibir en premio títulos de Almirante y armas de nobleza; hacer la guerra más homicida a la inocencia más pura; destruir los gobiernos establecidos por la voluntad de los pueblos; sacrificar millares de víctimas para levantar sobre ellas el trono de reyes lejanos; derramar sangre, matar, quemar; nada de esto es alteración del orden ni turbación del reposo y tranquilidad.

La obra del señor Sepúlveda en que dice que los españoles tienen derecho para subyugar a los indios no es subversiva y corre libremente por las manos de todos. Las mías, en que demostré que el gobierno de una nación no tiene derecho para subyugar a otra nación, son subversivas y deben ser probibidas (Valle, 1982: 192). 


\section{Hernán Cortes dialoga con el barón de Montesquieu}

El segundo diálogo es el que imaginó entre el conquistador de México, Hernán Cortés, y Montesquieu. En el comienzo, Cortés, como Colón en el primero, reivindica sus logros, alcanzados por su valor. En ambos casos, expresiones de soberbia de los conquistadores.

Llegué a las costas, fundé la ciudad de Veracruz, subí a México, puse grillas a su emperador, sometí la América septentrional, y la presenté a Carlos I. Tengo más títulos que César para decir: Veni, vidi, vinci. [...].

Con un puñado de españoles derroté a millares de mexicanos levanté en México las banderas de Castilla, y subyugué todas aquellas tierras.

Al barón, semejante cosa le parecía «un prodigio» y quería «saber cómo fue operado», pues no encontró respuesta en historias y romances que leyó. El relato de Antonio de Solís (Historia de la conquista de México, 1648) le parecía muy donoso.

La guerra injusta de los españoles que querían hacer esclavos a los indios que amaban sus independencia, es a sus ojos [los de Solís] la lucha de Dios que deseaba plantar la religión, y del diablo que la resistía (Valle, 1982: 193).

Valle no avanzó en lo que es evidente en el breve párrafo: el cuestionamiento de la doctrina de la guerra justa, elaborada por el dominico Francisco de Vitoria en 1538, que fue utilizada como argumento jurídico-político-religioso de la conquista.

El imaginario Cortés alega que el valor español contó con el positivo auxilio de Dios, ante lo cual Montesquieu responde:

¡Para devastar la obra más grande de sus manos! ¡Para destruir la inocencia y hollar la justicia!... Olvidemos el idioma que se habla en la tierra. El de estas regiones debe ser el de la verdad... ¿Podré decirla francamente? Lo que aseguró el triunfo de los españoles fue: $1^{\circ}$ El valor que inspira a una codicia insaciable la brillantez del oro y la plata. El candor de Moctezuma te enviaba presentes muy ricos para que te retirases de las costas; y estos presentes, avivando el amor a aquellos metales, te llevaban a la capital de su imperio. $2^{\circ}$ La disciplina de tus tropas. Cuerpos matemáticos formados a compás debían batir a masas desorganizadas. $3^{\circ} \mathrm{La}$ superioridad de armas. Era preciso que la artillería triunfase de las flechas. $4^{\circ} \mathrm{La}$ hipocresía, el ardid, la astucia. El engaño es en todos los países el instrumento con que el minimo se burla del máximo (Valle, 1982: 193).

Otra vez, como en el primer diálogo, la sed de metales preciosos ocupando el primer lugar en los objetivos de la conquista. El cuarto punto es una síntesis per- 
fecta del procedimiento felón con el que los invasores se aprovecharon al máximo de la ingenuidad y buena fe de los naturales, dando enseguida cuenta de numerosos ejemplos que avalaban su juicio.

Más adelante, Montesquieu apunta:

Es original la idea que se ha tenido de los indios. Alejandro VI los regaló a los reyes de España. Éstos donaron muchos de ellos a los cabos o adelantados [...]. Y se disciplinaron perros, y se les daba ración como a los soldados para que sofocasen y devorasen a los indígenas. El ganado vacuno, caballar o lanar ba merecido mejor opinión.

Ningún pontífice ha regalado hatos de ovejas a los reyes, ni los monarcas han hecho merced de los potros o cabros que pacen en los cortijos, ni hombre alguno ha dado instrucción a los perros para que maten las vacas y caballos.

El contrapunto entre el trato dado a los ganados y a los seres humanos nativos cuestiona la supuesta benevolencia de los conquistadores. De allí que cuando, a continuación, Cortés defiende esas donaciones papales y reales por haber producido «bienes inmensos a la América y a España», la sombra Montesquieu rebate:

A la América se han hecho los bienes siguientes: $1^{\circ}$ se mataron más de 15 millones de indios, asolando más de diez reinos mayores que toda España; ${ }^{\circ}$ se hizo merced de los que quedaron vivos a los adelantados o cabos, o encomenderos para que fuesen vasallos suyos y tributarios; $3^{\circ}$ se destruyeron todos los gobiernos que tenían establecidos en el centro de sus mismas naciones, y se les sometió a un gobierno distante, separado de ellos por la inmensidad del océano; $4^{\circ}$ se les mantuvo en pupilaje e ignorancia perpetua prohibiendo que viviesen en sus pueblos los individuos de clases que podían civilizarlos, y haciendo que América fuese en la extensión de la tierra un pueblo aislado, sin relaciones con los demás del mundo; $5^{\circ}$ se les condenó a trabajos destructores; no se les permitió el cultivo de artículos que podrían enriquecerlos; se les prohibió la industria fabril que pudiera disminuir sus miserias; y se les negó la facultad de montar una caballería; $6^{\circ}$ se les enviaron reos criminales para que fuesen pobladores de sus tierras y corruptores de sus costumbres. A España se han hecho los beneficios que siguen: $1^{\circ}$ se le despobló, sacando colonias de ella para poblar y tener sujeta a América; $2^{\circ}$ se depravó su moralidad abriendo a las pasiones los campos dilatados del oro corruptor; $3^{\circ}$ se encarecieron los jornales de sus trabajos y los artículos de su cultivo e industria por 1a abundancia de plata que se llevaba a sus puertos; $4^{\circ}$ se complicaron sus relaciones, y se le hizo sufrir guerras para conservar las Indias; $5^{\circ}$ se le obligó a ser ignorante para que América lo fuese también y no pasasen de la una, luces dañosas a la otra. 
[Cortés] El cálculo de indios muertos en la conquista es exagerado. Extranjeros, envidiosos de las glorias de España, alteran la verdad para llenar sus deseos.

[Montesquieu] No es extranjero el que ha computado 15 millones. Es don Fray Bartolomé de las Casas, obispo de Chiapas. Disminuye más de la mitad el número de muertos. ¿La sangre de siete millones de hombres será de pequeño valor? "Las mujeres de América se hacían abortar para que sus hijos no tuviesen amos tan crueles». [Valle cita aquí textualmente al barón en El espíritu de las leyes]. Los hombres excesivamente felices y los hombres extremadamente infelices son igualmente inclinados a la dureza (Valle, 1982: 195-196).

Valle, como la mayor parte de los dirigentes independentistas, enfatizaba el contrapunto entre lo ganado por España y lo perdido por América a raíz de la conquista y ulterior colonización del «Nuevo Mundo». Se trataba de encontrar en ese pasado de opresión las razones que justificaban la rebelión, la lucha por la independencia.

Cuando el falso Cortés le pregunta al falso Montesquieu si la riqueza puede ser causa de miserias, si el oro y la plata pueden serlo de miserias y desventuras, Valle responde apelando a una cita textual tomada de El espíritu de las leyes:

El oro y la plata son signos, o riqueza de representación. Duran mucho tiempo sin destruirse y sucede en ellos lo mismo que en las demás mercaderías. Cuando abundan se disminuye su valor porque representan menos cosas. Después de la conquista de México y de Perú, los españoles abandonaron las riquezas naturales para tener signos de riquezas. El oro y la plata eran muy raros en Europa; la que se llevó de Indias hizo que se duplicase la que había y entonces el precio de las cosas fue también doble del que tenían anteriormente. Los españoles trabajaron las minas. La plata se fue aumentando en Europa, y la ganancia disminuyendo para España. Supóngase que el gasto de la extracción del oro y la plata de las minas sea como 1 a 64. Duplicándose la cantidad de plata su valor baja una mitad menos, y el gasto llega a ser como 2 a 64. Las flotas que llevaban a España la misma cantidad de oro llevaban una cosa que valía la mitad menos y costaba la mitad más. Siguiendo sucesivamente la progresión del duplo, se descubre la causa de la impotencia de las riquezas de España. Doscientos años ha que se trabajan las minas. Figúrese que la masa de plata que hay ahora en el mundo sea a la que había antes del descubrimiento de las Indias como 32 a l, es decir, que se ha duplicado cinco veces. En doscientos años la misma cantidad de plata será a la que había antes de la conquista como 64 a 1. Si a los 200 años de haberse comenzado a trabajar las minas, 50 quintales de mineral dan 4, 5 o 6 onzas de oro, cuando sólo den 2, el minero no podrá sacar más que los gastos. Los reyes 
de España son como aquel monarca insensato que pidió a los dioses se convirtiese en oro cuanto tocase, y después se vio obligado a suplicarles que pusiesen término a su miseria (Valle, 1982: 197).

Más allá de lo acertado o no de lo cálculos realizados por Montesquieu, interesa destacar que para Valle era preciso fundamentar con sólidos argumentos las razones que hacían necesaria la independencia.

En el intercambio de palabras que sigue al precedente, Valle se ocupa de la espacialidad, de la territorialidad en relación con la gestión de gobierno.

El genio más prodigioso no podría gobernar bien un continente tan vasto como el de la América. El celo se debilita cuando se divide en multitud de pueblos dispersos en una extensión muy grande de tierras; y ese mismo celo es activo y enérgico cuando se fija en un espacio proporcionado a su fuerza. ${ }^{7}$ Condicionado a su fuerza. El gobierno de Castilla no puede administrar bien a España y a América. El resultado preciso de su ambición es el atraso de una y otra; la miseria, ignorancia y despoblación de las dos. Las conquistas de Oriente llevaron riquezas a Roma y con ellas su destrucción y ruina. Al momento en que España comenzó a ser señora de las Indias, empezó también a ser pobre o menos rica en Europa. Todo fue decadencia desde aquel instante en que se creía feliz.

Tras lo cual remata:

Los hijos de españoles son españoles en opiniones y sentimientos si nacen en España; y son americanos en uno y otro si nacen en América. Los primeros aman los fueros y prosperidad de España. Los segundos aman los derechos y prosperidad de América (Valle, 1982: 198).

Es digno de destacar el contrapunto conceptual: unos, por los fueros; otros, por los derechos. Es la disyunción entre súbditos y ciudadanos.

\section{Las sombras de Monteagudo y las de Valle}

Como en el «Diálogo entre Atahualpa y Fernando VII», de Monteagudo, en el de Colón con Rousseau y en el de Cortés con Montesquieu, Valle se empeña en una argumentación que desnuda y condena la conquista y la colonización. En ese sentido, no difiere de la esgrimida trece años antes por Monteagudo, que Altuna ha sintetizado muy bien.

¿Sobre qué dialogan estos muertos/estas sombras? Los tópicos son explícitos: el carácter de la conquista, la evangelización, las razones económicas, políticas y

7 Habría que comparar la argumentación que Valle hace en este «Diálogo» entre Cortés y Montesquieu respecto de gobernar un espacio amplio con la sostenida en favor de la confederación de la América que fue española, tal como fue formulada al año siguiente en «Soñaba el Abad...». 
religiosas, la independencia. «El punto de partida y, a la vez, centro de la argumentación, lo constituyen las nociones de tiranía y obediencia forzada, frente a la de soberanía popular», concluye Altuna a propósito de Monteagudo, pero extensible a Valle (Altuna, 2002: 3-4).

La sombra Atahualpa de Monteagudo — señala Altuna, igualmente extensible a la sombra Rousseau de Valle- «rebate el argumento de la evangelización, contra argumentando ella no justifica el despojo del poder ni el dominio». Cuando, a su vez, Fernando VII apela al juramento de fidelidad y vasallaje, le abre la puerta a Atahualpa para «explayarse acerca del "espíritu de libertad" del hombre y su imprescriptibilidad; la consecuencia que se sigue es que no existió libertad en la aceptación de ese vínculo, sino terror al despotismo», es decir, en clave rousseauniana, la demostración de que la monarquía de facto que España estableció en América «es ilegítima, puesto que existe fuera de todo pacto social y se funda en el interés individual» (Altuna, 2002: 5). Cabe acotar que esa había sido también la argumentación de Mariano Moreno en Buenos Aires (1810).

Altuna hace una alusión expresa a los «Diálogos» de Valle como otro ejemplo de «la difusión que este tipo de textos tuvo en América durante el período», y en los que el centroamericano «recupera el pasado precolonial - lo "reescribe" - y argumenta respecto de la independencia, a través de las voces de personajes tomados de la tradición clásica - Filántropo, Palemón- y de la historia - Cristóbal Colón y Rousseau, Carlos I y Carlos III—». Tras ello recuerda que en 1822 del Valle y Monteagudo se encontraron en Guatemala (Altuna, 2002: 15, nota 2). Adicionalmente, añadimos, ese encuentro fue un momento importante en la formulación de proyectos de unidad latinoamericana, tal como la postularán luego Simón Bolívar (convocatoria al Congreso de Panamá, 1824) y el propio Monteagudo («Ensayo sobre la necesidad de una federación general entre los pueblos hispano-americanos y plan de su organización», 1825).

\section{Carlos I Habsburgo dialoga con Carlos III Borbón}

Retornando a los «Diálogos» de Valle, cabe señalar que el tercero de ellos es de otro tenor, ya que es entre dos reyes españoles: Carlos I (1500-1558), Habsburgo, y Carlos III (1716-1788), Borbón. La elección no fue caprichosa, toda vez que fueron expresión de dos momentos cruciales de la historia española. Durante el largo reinado del primero, la expansión española alcanzó escala planetaria. Fue durante esas décadas que Hernán Cortés conquistó México y originó Nueva España; Cristóbal Olid sometió sin resistencia al pueblo purépecha (o tarasco), en el actual estado mexicano de Michoacán, aunque casi enseguida Nuño de Guzmán llevó adelante una política de terror contra los nativos; Francisco de Mon- 
tejo inició la conquista de Yucatán; Pedro de Alvarado ocupó América Central, posibilitando la creación del Reino de Guatemala; Francisco Pizarro conquistó el Incario, sentando las bases para establecer el virreinato del Perú; Gonzalo Jiménez de Quesada derrotó a los muiscas y otros pueblos originarios de la actual Colombia, territorio del nuevo Reino de Nueva Granada (que el Borbón Felipe V convirtió en virreinato en 1717); Sebastián de Benalcázar y Francisco de Orellana salieron en busca de El Dorado, expedición fracasada que, en contrapartida, hizo conocer a los europeos la Amazonía y el inmenso río que da nombre a la región; Juan Sebastián Elcano completó el viaje iniciado por Fernando de Magallanes, que no solo fue el primero en dar la vuelta al mundo (1522), sino que también posibilitó la ocupación, conquista y colonización de las Filipinas y las Marianas, islas que España detentó hasta su derrota en la guerra contra Estados Unidos (1898). Fueron los tiempos del Imperio donde «nunca se ponía el sol».

Carlos III, en cambio, fue la máxima expresión del reformismo borbón y del despotismo ilustrado, experiencia con la que simpatizaba Valle. Podría decirse que ese rey quiso hacer una España burguesa en un país donde la burguesía era prácticamente inexistente, salvo en Cataluña, región sin ningún aprecio por los Borbones.

Valle los puso a dialogar para mostrar el antagonismo entre uno y otros, entre dos formas de absolutismo: uno, retrógrado; el otro, reformista.

Valle muestra a Carlos III vanagloriándose de los logros de su gobierno:

España era un cuerpo lánguido, sin alma que lo animase y diese energía. Era preciso regenerarla; y este fue el plan de mi reinado. Puse al frente de los negocios a un hombre digno del primer ministerio de la nación; protegí la agricultura, la industria y el comercio; establecí sociedades económicas de amigos de su patria para que diesen luces y premios a los labradores y artesanos; establecí cátedras de agricultura y difundí los conocimientos útiles por medio de los periódicos agrónomos y mercantiles; fundé poblaciones nuevas en los campos más fértiles; abrí canales que facilitasen el riego y llevasen la fecundidad a las tierras más incultas; erigí el Banco Nacional que da vida a la circulación; establecí la compañía de Filipinas; ajusté con la Puerta Otomana el Tratado que abrió el Levante a las especulaciones del español; extendí las relaciones comerciales abriendo doce puertos en España y veinticuatro en América; quité las trabas que lo ligaban, y lo declaré libre entre americanos y españoles; di al jardín botánico y a la academia de pintura, escultura y arquitectura toda la protección que merecen unos establecimientos tan importantes; crié y enriquecí el gabinete magnífico de historia natural; envié al Nuevo Mundo expediciones científicas que han engrandecido el sistema de los conocimientos humanos; ordené la redacción de un código le- 
gislativo digno de los progresos del siglo, y mandé con este fin que se formase una comisión de juristas ilustrados; mejoré la milicia, instruyéndola en la táctica que dio tanta superioridad a las fuerzas de Prusia; reformé los planes de estudios en las universidades; fomenté la ilustración universal; moderé las instituciones severas de la Inquisición; expelí de todos mis dominios a los jesuitas; y humillé al gobierno británico auxiliando la insurrección de sus colonias y reconociendo su independencia.

Los logros que celebra el Borbón horrorizan al Habsburgo:

¿Qué has hecho, Carlos? ¿Puedo creer que haya rubricado tales decretos la mano de un rey de España? ¡Ah! Yo debí ser eterno en el trono de Madrid. Se perdió la obra más grande de mis desvelos. ¡Qué trastorno! ¿Qué error! ¿Qué injusticia!

[Carlos III] Abrir las fuentes de riqueza ¿será trastorno? ¿Disipar tinieblas será error? ¿Ilustrar a los hombres será injusticia?

[Carlos I] Pero ¿ilustrando a los españoles, no conocerán sus derechos? Difundiendo luces en el mundo antiguo, ¿no pasarán sucesivamente al Nuevo? Auxiliando la insurrección de las colonias inglesas ¿no se preparará la de los españoles? Tú olvidaste el secreto de los reyes. Yo abrí los cimientos de una monarquía universal, y tú has abierto el abismo a donde irá a hundirse la de España. Fomentando la ilustración, los españoles recordarán sus fueros y libertades habrá entre ellos y sus reyes y señores naturales una lucha peligrosa que al fin hará derramar sangre; pedirán primero cortes y querrán después Constitución; se sucederán unas a otras las revoluciones; América aprovechará los momentos; pasarán a ella las luces odiosas de España; se oirán en aquellas regiones voces que no deben resonar en su atmósfera; se imitará el ejemplo de los anglo-americanos: se proclamará independencia; y el mundo viejo quedará separado del nuevo; [... ]. Para tener paz, silencio y tranquilidad, es preciso jurar reyes absolutos. Para que existan los soberanos dueños de vidas y haciendas, deben ser ignorantes los pueblos; $y$ para conservar América, debe haber Inquisición en España. La luz es un fluido tan sutil que pasa por los poros más diminutos de los cuerpos más densos. Sólo la mano diestra de los Torquemadas y Mendozas puede impedir que penetren esos rayos peligrosos que alumbran, pero queman y abrasan. No debe baber otra luz que la de las bogueras en el silencio y tranquilidad de la noche.

El Carlos III que habla a través de Valle acota:

Las revoluciones nacen del choque de los gobiernos con los pueblos. Cuando un gobierno es sabio [cursivas de Valle] en observar la voluntad general de la nación y antes de conmoverse ésta manda ejecutar lo que desea ella misma, no hay revoluciones, ni muertes, ni horrores. Las reformas no parecen obra de los pueblos. Se bacen en paz y sosiego por la mano misma del gobierno. Son una transición 
moral; no son una reacción física. Lo que hace derramar sangre es la resistencia de los gobiernos obstinados en hacer oposición al voto universal de las naciones. Entonces, hay cadáveres, y sobre ellos triunfa por fin lo que es justo (Valle, 1982: 199-200).

Aquí es clara la posición reformista de Valle, su postura de llevarla adelante mediante los hombres ilustrados, al menos hasta que la educación se universalice, objetivo este que consideraba condición necesaria para hacer viable una república independiente. La reforma como medio de evitar la revolución fue un leitmotiv de su pensamiento y su acción política, de su decir y su hacer. Asimismo, adviértase que no rechazaba la eventualidad de la apelación a la violencia.

\section{Dos antiguos, Filántropo y Palemón, dialogan brevemente}

El cuarto y último diálogo pergeñado por Valle es entre dos antiguos, Filántropo y Palemón. Es muy breve, apenas una página. En él resaltan los conceptos consignados a continuación, que, como se leerá, refuerzan los fundamentos de la idea de la independencia. Dice el primero:

o nos extraviemos. Fijémonos en esta verdad. La independencia de una nación regida por gobierno lejano es ley de la naturaleza, tan constante como todas las demás del mundo físico [cursivas en el original].

Acota el segundo:

El marqués de Laplace escribió un Ensayo filosófico sobre las probabilidades; y en él dijo estas palabras que aprendí de memoria: «es contra la naturaleza de las cosas querer que un pueblo esté sometido a otro, separado de él por un océano vasto o por una distancia grande. Se puede afirmar que esta causa constante (la de la distancia) uniéndose sin cesar con las causas variables que obran en el sentido y desarrolla el curso del tiempo terminará al fin dando al pueblo sometido su independencia natural».

Filántropo cierra el diálogo aseverando:

Es una verdad que tiene a su favor el testimonio universal de todas las historias. En ellas se ve el cuadro de los conquistadores que han desenvuelto sus resortes para arrojar la opresión...

A lo largo de los cuatro diálogos, José Cecilio del Valle argumentaba, desde distintos ángulos y apelando a diferentes autoridades, en favor de aquello que para él era ineluctable: la independencia. 


\section{Cierre (provisorio)}

Esta breve contribución llega a su fin. Deja abiertas eventuales líneas exploratorias sobre la importancia de los diálogos de los muertos en el siglo xix, tan denso en agitaciones y confrontaciones ideológicas de distinto tenor, tales, como, por ejemplo, los fundamentos del nuevo orden político o la construcción de imaginarios sociales, entre otras. Hacemos nuestras las palabras de Carolina Carvajal: «[... el género del diálogo de los muertos podría instalarse, como una interesante puerta de entrada al estudio de un periodo fundacional donde se busca construir identidad y se configuran los rasgos fundamentales del futuro político, social y económico de los países americanos, cuyas tensiones se prolongan hasta el día de hoy» (Carvajal, 2017: 17).

Hoy no se estila este tipo de ejercicios de literatura para la lucha política e ideológica, pero detenerse en los del siglo xix bien puede contribuir a explicar los términos de confrontaciones que, mal o bien, se dirimieron por entonces, pero que, en diferentes ámbitos de nuestras sociedades, sobre todo en las estructuras mentales, todavía hoy están presentes en las tensiones que atraviesan aquellas, signos inequívocos de que no fueron resueltas, siguen siendo tareas por hacer, entre ellas, parafraseando a Eduardo Galeano, la definitiva independencia. Sí, sin duda, tarea pendiente e inconclusa, pero, también, irrenunciable, tanto como latinoamericanos como en calidad de latinoamericanistas. En esa tarea pendiente, hoy más que ayer el poder de la escritura es fenomenal, como lo muestra la importancia de las falsas noticias y las redes en la lucha política, en la confrontación por la hegemonía. Como vimos, José Cecilio del Valle escribió: El engaño es en todos los países el instrumento con que el mínimo se burla del máximo. ¿No resultan palabras rigurosamente actuales? 


\section{Bibliografía citada}

Alonso, L. E. (1998). La mirada cualitativa en sociología. Una aproximación interpretativa. Madrid: Fundamentos.

Altuna, E. (2002). Un letrado de la emancipación: Bernardo de Monteagudo. Andes, 13, enero-diciembre. Universidad Nacional de Salta. Disponible en: $<$ https://www.redalyc.org/articulo.oa?id=127/12701302>

Andries, L. (2004). Les dialogues des morts au Xviıre siècle. Séminaire AGONSéance, 4. Disponible en: <http://www.agon.paris-sorbonne.fr/en/ressources-en-ligne/comptes-rendus/les-dialogues-des-mortsau-xviiie-siecle $>$.

Anna, T. (1985). «La independencia de México y América Central». En Leslie Bethell (ed.). Historia de América Latina. 5. La independencia. Barcelona: Crítica.

Anna, T. (2003). «Casos de continuidad y ruptura: Nueva España y Capitanía General de Guatemala». En Germán Carrera Damas (dir.) y John V. LomBArdi. Historia General de América Latina. Volumen V. Madrid: Ediciones UNESCO y Trotta.

Ansaldi, W. y Giordano, V. (2016). América Latina. La construcción del orden. Tomo 1. De la colonia a la disolución de la dominación oligárquica. Ciudad Autónoma de Buenos Aires: Ariel (1. a ed. ampliada, revisa y actualiza la de 2012).

Bajtín, M. (1986). Problemática de la poética de Dostoievski. México DF: Fondo de Cultura Económica. (Hay ediciones posteriores).

Carvajal, C. (2017). «El diálogo de los muertos como una alegoría del lugar de enunciación intelectual decimonónico: El caso de Juan Rafael Allende».Disponible en línea en: <https://www.researchgate.net/publication/319855513_ El_dialogo_de_los_muertos_como_una_alegoria_del_lugar_de_enunciacion_del_intelectual_decimononico_El_caso_de_Juan_Rafael_Allende>

Domingues, J. (2012). Pourquoi les morts sont-ils si extravagants? Carnets, IV (4), 47-62.

Eissen, A. (2007). «Pour un étude diachronique du dialogue des morts». Otrante, (22), 7-24.

Gómez, A. (2010). José del Valle. Un ilustrado centroamericano. Guatemala: Universidad Francisco Marroquín-Instituto Democracia y Mercado-Universidad del Desarrollo.

Gómez, A. (2011). José del Valle: el político de la independencia centroamericana. Guatemala: Universidad Francisco Marroquín. 
Halperin Donghi, T. (1985). Reforma y disolución de los imperios ibéricos 17501850. Madrid: Alianza. (Se trata del tomo 3 de la Historia de América Latina dirigida por Claudio Sánchez Albornoz).

Henrichот, M. (2008). «La fiction infernale dans les dialogues del morts». En A. Bouloumié. Les Vivants et les Morts. Littératures de l'entre-deus-mondes. Paris: Imago.

Hörl, S. G. (2006). «La enunciación en Los Diálogos de los Muertos de Luciano Samóstata». Stylos, 15. Disponible en: <http://bibliotecadigital.uca.edu. $\mathrm{ar} /$ repositorio/revistas/enunciaciondialogosmuertos.samosata.pdf $>$

Pinto Soria, J. C. (1993). «La independencia y la Federación (1910-1840)». En Héctor Pérez Brignoli (ed.). De la Ilustración al liberalismo (1750-1870). Madrid: Sociedad Estatal Quinto Centenario y Facultad Latinoamericana de Ciencias Sociales. (Se trata del tomo III de la Historia General de Centroamérica, coordinada por Edelberto Torres-Rivas, 6 tomos).

Vian Herrera, A. (2001). «Interlocución y estructura de la argumentación en el diálogo: algunos caminos para una poética del género.» Criticón, 8182, 157-190. Disponible en: <https://cvc.cervantes.es/literatura/criticon/ PDF/081-082/081-082_159.pdf>

Volant. É. (2012). Dialogues des morts. En Encyclopédie sur la mort. Disponible en: <http://agora.qc.ca/thematiques/mort/dossiers/dialogues_des_morts>

\section{Fuente édita}

Valle, J. C. del (1930). Obras de José Cecilio del Valle, compiladas por José del Valle y Jorge del Valle Matheu. Tomo II. El Amigo de la Patria. Edición digital a partir de Guatemala, Tipografía Sánchez \& de Guise, 1930, disponible en: <http://www.cervantesvirtual.com/obra/obras-tomo-2-el-amigo-de-lapatria/>

VAlle, J. C. del (1982). Obra escogida. Selección, prólogo y cronología por Mario García Laguardia, Biblioteca Ayacucho, volumen XCVII, Caracas. 